\title{
Qualidade da Coparentalidade e o Estresse em Pais de Crianças com Paralisia Cerebral ${ }^{1}$ \\ Coparenting Quality and Stress in Parents of Children with Cerebral Palsy
}

\author{
Katiane da Costa CUNHA ${ }^{2}$ \\ Ivete Furtado Ribeiro CALDAS 3 \\ Fernando Augusto Ramos PONTES 4 \\ Edson Marcos Leal Soares RAMOS \\ Priscilla Bellard Mendes de SOUZA ${ }^{6}$ \\ Simone Souza da Costa SILVA ${ }^{7}$
}

\begin{abstract}
RESUMO: O objetivo deste artigo foi verificar a associaçăo entre a qualidade da coparentalidade e o estresse em pais de crianças com paralisia cerebral (PC). Trata-se de um estudo transversal e descritivo. Foram incluídos 81 pais de crianças com até 12 anos de idade diagnosticadas com PC. Os instrumentos utilizados foram Inventário sociodemográfico, Escala de classificação funcional motora grossa, Índice de estresse parental e Questionário de coparentalidade submetidos na Técnica de Análise de Correspondência (ANCOR). Altos níveis de estresse total estâo associados a elevados índices de estresse nas subescalas sofrimento parental, interação disfuncional pai e filho e criança difícil. Os pais avaliados no Questionário de Coparentalidade com baixa cooperação foram registrados com elevados índices de estresse na subescala sofrimento parental. Os dados mostraram relaçáo significativa entre a qualidade da coparentalidade e o nível de estresse em pais de crianças com PC.
\end{abstract}

PALAVRAS-CHAVE: Coparentalidade. Estresse parental. Cuidados parentais. Paralisia cerebral.

ABSTRACT: The aim of this paper is to verify the association between quality of co-parenting and stress in parents of children with cerebral palsy (CP). This is a cross-sectional and descriptive study. Eighty-one parents of children up to twelve years old diagnosed with CP were included. The instruments used were Sociodemographic Inventory, Gross Motor Functional Rating Scale, Parental Stress Index and Coparenting Questionnaire. High levels of total stress are associated with stress levels in parent distress sub-items, dysfunctional parent-child interaction, and difficult child. The parents evaluated in the Coparenting Questionnaire with low cooperation were registered with high levels of stress in the subscale parental suffering. The data showed a significant relationship between the quality of coparenting and the level of stress in parents of children with CP.

KEYWORDS: Coparenting. Parental stress. Parental care. Cerebral palsy.

\footnotetext{
${ }^{1}$ https://doi.org/10.1590/1980-54702021v27e0010

${ }^{2}$ Pós-doutorado em Teoria e Pesquisa do Comportamento. Núcleo de Teoria e Pesquisa do Comportamento, Universidade Federal do Pará. Belém/Pará/Brasil. E-mail: katianefisio@yahoo.com.br. ORCID: https://orcid.org/0000-0001-5361-5090

${ }^{3}$ Doutora em Neurociências e Biologia Celular. Universidade do Estado do Pará, Campus VIII/Marabá. Marabá/Pará/Brasil. E-mail: ivbeiro@yahoo.com.br. ORCID: https://orcid.org/0000-0002-2095-101X

${ }^{4}$ Doutor em Psicologia. Núcleo de Teoria e Pesquisa do Comportamento, Universidade Federal do Pará. Belém/Pará/Brasil. E-mail: farp1304@gamil.com. ORCID: https://orcid.org/0000-0001-9569-943X

${ }^{5}$ Doutor em Engenharia de Produção. Programa de Pós-Graduação em Segurança Pública Universidade Federal do Pará. Belém/ Pará/Brasil. E-mail: ramosedson@gmail.com. ORCID: https://orcid.org/0000-0001-5425-8531

${ }^{6}$ Doutora em Teoria e Pesquisa do Comportamento. Núcleo de Teoria e Pesquisa do Comportamento, Universidade Federal do Pará. Belém/Pará/Brasil. E-mail: pribellard@gmail.com. ORCID: https://orcid.org/0000-0003-2148-510X

${ }^{7}$ Doutora em Psicologia, Núcleo de Teoria e Pesquisa do Comportamento, Universidade Federal do Pará. Belém/Pará/Brasil. E-mail: symon.ufpa@gmail.com. ORCID: https://orcid.org/0000-0003-0795-2998
} 


\section{INTRODUÇÁo}

Tem sido crescente o número de pesquisas que estudam as associaçóes entre as variáveis que influenciam o desenvolvimento dos filhos, tais como: estresse parental, resiliência, auto eficácia etc. (Cunha et al., 2017; Lima et al., 2016; Souza \& Crepaldi, 2019). Tal interesse assenta-se sob as evidências demonstradas pelas pesquisas em desenvolvimento humano, que, dentre outros fatores, mostram relação desse fenômeno com o funcionamento familiar, com as relações parentais e as características psicológicas dos pais e dos filhos (Souza \& Crepaldi, 2019).

No que tange às relaçóes familiares, a dinâmica de cuidados existente entre pais e filhos, ou seja, a coparentalidade, tem motivado os pesquisadores (Frizzo et al., 2019; Mosmann et al., 2018) na elaboração de pesquisas que investigam os impactos dessa relação sobre o desenvolvimento das crianças. A coparentalidade, então, tem sido definida como a relação de compartilhamento de açóes e de tarefas nos cuidados parentais oferecido a uma ou mais crianças, independentemente da existência de laços consanguíneos entre os cuidadores em si e destes para com as crianças, porém a forma como essa relação se estabelece depende de cada díade, não havendo necessariamente uma obrigatoriedade de igualdade na divisão dos cuidados (Frizzo et al., 2019).

Diferentes modelos teóricos têm sido propostos para compreender a coparentalidade (Feinberg, 2003; Van Egeren \& Hawkins, 2004). Entretanto, na presente pesquisa, foi utilizada a proposta apresentada por Margolin et al. (2001), que sustenta a noção de coparentalidade em três conceitos fundamentais, a saber: cooperação, triangulação e conflito.

A cooperação coparental consiste na concordância com o compartilhamento das responsabilidades parentais, o quanto os pais se apoiam, valorizam e se respeitam mutuamente, implicando padróes relacionais positivos dentro da divisão de cuidados, e trajetórias desenvolvimentais saudáveis às crianças. Por sua vez, a triangulação coparental refere o quanto cada figura parental constrói barreiras entre as crianças e o parceiro, expondo-as a verdadeiras disputas parentais manipulatórias, pois a criança vê-se diante de uma escolha forçada, obrigada a preferir um dos cuidadores em função da escolha do outro cuidador, configurando-se como uma forma de conflito velado, extremamente prejudicial ao desenvolvimento da criança. Já o conflito coparental diz respeito às desestabilidades, às situaçóes e às brigas explícitas que envolvem situaçóes mal resolvidas e desacordos entre as figuras parentais, principalmente envolvendo situaçóes pertinentes às diferenças de cuidados (Lamela et al., 2010).

Surgida pela primeira vez nas pesquisas que investigavam famílias em processo de separação (Romero, 2015), alguns autores têm encontrado evidências consubstanciais nas correlaçóes existentes entre conflitos coparentais e o desencadeamento de problemas de comportamentos internalizantes, como ansiedade e depressão, e externalizantes, como agressividade e baixo rendimento escolar dos filhos (Lamela \& Figueiredo, 2016). Em um cenário mais amplo, a coparentalidade tem sido estudada nos mais diferentes contextos de desenvolvimento, predominantemente no típico (Dantas et al., 2018), muito embora tenha sido crescente a relação entre a coparentalidade e o desenvolvimento atípico, como crianças portadoras de deficiências físicas ou mentais, como a paralisia cerebral (Afonso et al., 2016). Segundo Souza e Crepaldi (2019), o aspecto cooperação, que constitui a coparentalidade, exerce poder protetivo ao desenvolvimento das crianças, principalmente no que tange ao seu ajustamento psicológico, uma 
vez que resguarda a percepção infantil dos conflitos coparentais, apontados como disruptivos ao desenvolvimento da prole.

Nesse sentido, muitos conflitos emergem, na maioria dos casos, em função de inúmeros fatores, sendo um dos mais comuns o estresse parental, definido como um desequilíbrio que ocorre quando os pais avaliam que os recursos que dispóem são insuficientes para lidar com as exigências de seu papel (Cunha et al., 2017). Além de comprometer a saúde mental e física dos cuidadores, o estresse parental também pode influenciar negativamente na relação conjugal, uma vez que a dinâmica de cuidados parentais envolve diferentes movimentos - satisfação, recompensa, demanda e sobrecarga -, podendo causar danos ao bem-estar físico, emocional e social dos pais (Skreden et al., 2012), implicando exercício coparental conflituoso com efeitos negativos ao desenvolvimento dos filhos, principalmente se estes já trazem características desenvolvimentais específicas, como a PC, que requer coordenação conjunta de múltiplos cuidadores, estando estes com boa saúde emocional.

A PC é caracterizada diferentemente, de acordo com a localização da lesão, destacando-se por ser um distúrbio permanente, não variável, do movimento e da postura, devido a defeito ou lesáo náo progressiva, do cérebro no começo da vida. Demanda dos cuidadores prontidão absoluta e constantes cuidados parentais, uma vez que quanto mais ampla for a área cerebral afetada, maior comprometimento funcional e baixa autonomia desenvolvimental terá a criança (Papageorgiou et al., 2019).

Dessa forma, devido à cronicidade do quadro, a criança com PC requer, além dos dispositivos emocionais dos cuidadores, como baixo nível de estresse, rede de apoio social e uma coparentalidade positiva, recursos financeiros suficientes que possam garantir intervenções terapêuticas que resultem em evoluçóes desenvolvimentais satisfatórias (Cunha et al., 2017). Entretanto, algumas famílias de crianças com PC acumulam, além das fragilidades inerentes à condição da deficiência, restriçóes nos recursos, sendo essa combinação a base dos conflitos entre os cuidadores (Afonso et al., 2016). Nesse sentido, o objetivo do presente estudo foi verificar a associação entre a qualidade da coparentalidade e o estresse em pais de crianças com PC. A hipótese sustentada é a de que, em contextos em que há presença de baixa renda, limitaçóes físicas e/ou funcionais na prole e níveis elevados de estresse entre os pais, há maiores índices de conflito coparental entre os cuidadores.

\section{Método}

Nesta seção, apresentam-se as características do estudo e dos participantes, os instrumentos utilizados para a coleta de dados e o procedimento e, por fim, os processos para análise e tratamento dos dados.

\subsection{Características do ESTUdo E PARTICIPANTES}

Trata-se de um estudo transversal e descritivo. Foram incluídos, na pesquisa, pais de crianças com até 12 anos de idade diagnosticadas com PC (CID 10-G80), sem qualquer tipo de alteração genética e/ou Transtorno do Espectro Autista (TEA), resultando em 81 pais. A pesquisa foi aprovada pelo Comitê de Ética e Pesquisa com seres humanos da Universidade Federal 
do Pará (UFPA) expressa no Parecer 473.140/11.2013, respeitada a Resolução do Ministério da Saúde CNS/MS No 466, de 12 de dezembro de 2012, com a participação condicionada à assinatura do Termo de Consentimento Livre e Esclarecido (TCLE) do entrevistado.

\subsection{INSTRUMENTOS}

Foram utilizados quatro instrumentos:

1. Inventário sociodemográfico (ISD) - construído pelos pesquisadores do Laboratório de Ecologia do Desenvolvimento da Universidade Federal do Pará (UFPA) com o objetivo de caracterizar as famílias investigadas e as crianças com PC. Para tanto, foi estruturado em itens referentes aos aspectos socioeconômicos, composição e história familiar, características da criança e de seu genitor.

2. Escala de Classificação Funcional Motora Grossa (GMFCS) - utilizada para avaliar a criança em cinco níveis (I, II, III, IV e V) de acordo com a idade, considerando o que consegue realizar em termos da função motora grossa. No nível I, a criança consegue mover-se sem restriçóes; no nível II, anda sem auxílio de aparelhos e muletas, tem limitações para andar fora de casa e na comunidade; no nível III, a criança consegue andar com auxílio de andadores ou muletas, tem dificuldades para andar fora de casa e na comunidade; no nível IV, anda com auxílio externo, com limitaçóes e necessita de cadeira de rodas para andar fora de casa e na comunidade, e apresenta atividades manuais limitadas; e no nível V, a mobilidade é gravemente limitada, mesmo com aparelho e adaptações, necessitando de assistência total (Palisano et al., 2007).

3. Índice de Estresse Parental (Parental Stress Index - PSI) - aplicado com o objetivo de aferir o nível de estresse percebido pelos pais. Nesta pesquisa, foi utilizada a versão reduzida (PSI/SF) composta por 36 itens, cuja versão completa foi validada para o português do Brasil (Pereira et al., 2016). O PSI/SF é usado em pesquisas em todo o mundo para avaliação do estresse de pais, incluindo pais de crianças com PC (Lima et al., 2016). Esse teste engloba o estresse total e três subescalas (sofrimento parental, interação disfuncional pai-filho, criança difícil). A soma dos pontos atribuídos a cada item define o escore total, que pode variar de um mínimo de 36 pontos a um máximo de 180 pontos. $O$ ponto de corte para o nível de estresse clínico é acima de 94 pontos, no estresse total. Na subescala "sofrimento parental", o ponto de corte é acima de 33; nas "interaçóes disfuncionais pai-filho", o ponto de corte é acima de 28; e acima de 37 na "criança difícil”. Para cada questão investigada, existe um conjunto de opçôes em uma escala do tipo Likert de cinco pontos (de 1 = discordo totalmente a 5 = concordo totalmente).

4. Questionário de coparentalidade - baseado no trabalho de Margolin et al. (2001), foi utilizado nesta pesquisa para avaliar a coparentalidade daqueles que cuidavam das crianças com PC. O instrumento é formado por uma escala Likert de cinco pontos, contendo 14 itens que avaliam a coparentalidade em função de três subescalas, a saber: cooperação (itens 1-5), triangulação (itens 6-9) e conflito (itens 10-14), com respostas que são pontuadas da seguinte forma: (1) para a resposta nunca, (2) para raramente, (3) às vezes, (4) normalmente e (5) sempre. Esse instrumento apresenta boa consistência interna com valores de alfa de Cronbach variando de .69 a .87. 


\subsection{Procedimento de coleta}

A coleta dos dados ocorreu no Hospital Universitário Bettina Ferro de Souza. Esse serviço é constituído por uma equipe multiprofissional, fundado em 2002, e, desde então, é considerado como referência na Regiāo Amazônica para o diagnóstico e o acompanhamento de crianças de até 12 anos de idade com alteraçóes do crescimento e do desenvolvimento.

Os participantes foram abordados individualmente e entrevistados na sala de espera do referido hospital nos dias em que as crianças possuíam atendimentos agendados. Nessa abordagem, eram-lhes feitas explicaçóes acerca da pesquisa e realizado o convite a participar. Mediante o aceite, o TCLE era assinado, e os instrumentos aplicados na seguinte sequência: $1^{\circ}$ ) ISD; 20) GMFCS; 3o) Índice de Estresse Parental; e 4º) Questionário de coparentalidade. A aplicação da GMFCS foi realizada por uma fisioterapeuta componente da equipe de pesquisa. A duração média de aplicação de todos os instrumentos foi de 60 minutos. $\mathrm{O}$ pesquisador lia em voz compassada e em bom tom cada instrumento, e as perguntas relacionadas, o participante respondia oralmente. As respostas eram registradas pelo pesquisador nos impressos dos instrumentos.

\subsection{AnÁlise E TRATAMENTO DOS DADOS}

A base de dados de Statistical Package for the Social Sciences (SPSS), versão 22.0, foi utilizada para a análise estatística descritiva dos dados do ISD e GMFCS. Os dados de coparentalidade foram submetidos na Técnica de Análise de Correspondência (ANCOR) com o auxílio do aplicativo Statistica, versão 6.0. Finalmente, os dados do estresse total do PSI/SF e suas subescalas foram cruzados com o índice geral e as subescalas do questionário de coparentalidade pela ANCOR.

De acordo com a literatura (Ramos et al., 2008), quando utilizada a análise de correspondência simples, as associaçóes são propagadas em um plano bidimensional; logo, a soma do percentual de inércia das dimensóes 1 e 2 deve ser igual ou superior a $70 \%$ para que os resultados sejam válidos. Para saber qual é a probabilidade de uma categoria de variável estar associada com outra foi necessário calcular o coeficiente de confiança $(\gamma)$. As associaçóes entre as categorias são consideradas significativas quando o valor do coeficiente de confiança indica probabilidades moderadamente significativas, isto é, quando $50 \% \leq \gamma \times 100<70 \%$; ou, quando o valor do coeficiente de confiança indica probabilidades fortemente significativas, ou seja, quando $(\gamma) \geq 70,00 \%$.

\section{Resultados}

Os achados estão dispostos em duas grandes categorias: dados sociodemográficos e associação entre coparentalidade e estresse parental.

\subsection{Dados SOCIODEMOGRÁFICOS}

Verificou-se que $97,5 \%$ dos cuidadores principais eram do sexo feminino, com idade média de 33,1 anos (DP=8,7), 75,3\% eram casados, 92,6\% cursaram até o Ensino Médio, $80,2 \%$ eram do lar e 79,0\% revelaram renda mensal de até dois salários-mínimos, sendo 84,0\% beneficiários de programas do governo. Quanto às crianças com PC, verificou-se que 54,3\% 
eram do sexo feminino, com idade média de 6 anos (DP=2,9) e peso aproximado de 17,8 quilos (DP=6,4), sendo em 42,0\% dos casos o primeiro filho. De acordo com a GMFCS, seis $(7,4 \%)$ foram classificadas no nível I, oito $(9,9 \%)$ no nível II, 13 (16,0\%) no nível III, 16 (19,8\%) no nível IV e 38 (46,9\%) no nível V.

Em relação ao recebimento do diagnóstico, as mães foram quem receberam a notícia em 66,7\% dos casos, ocorrendo antes dos 12 meses de idade de seu filho (82,0\%). Dentre as principais causas atribuídas à PC, destacou-se a perinatal (54,3\%) devido a quadros de prematuridade e anóxia (45,7\%). Por fim, o tempo entre o diagnóstico e o início do atendimento especializado foi de até 2 meses (48,2\%), com destaque para a equipe de reabilitação composta por fisioterapia, fonoaudiologia e terapia ocupacional em $43,2 \%$ dos casos.

\subsection{AsSociaÇÁo ENTRE COPARENTALIDADE E ESTRESSE PARENTAL}

Os dados foram organizados em (1) associação entre o estresse total do PSI e suas subescalas, (2) cruzamento entre o estresse total do PSI e suas subescalas e o índice de coparentalidade geral e (3) cruzamento entre o estresse total e suas subescalas e as subescalas do questionário de Coparentalidade.

A Tabela 1 mostra resultados da associação entre índice de estresse parental e suas subescalas. Pode-se observar a forte associação entre os altos níveis de estresse total e suas subescalas, bem como os baixos níveis de estresse total e suas subescalas. Nota-se que altos níveis de estresse total estavam associados a também elevados índices de estresse nas subescalas sofrimento parental (13.25 (100.0)), interação disfuncional pai e filho $(9.80(100.00))$ e criança difícil (11.55(100.00)). Por outro lado, evidencia-se baixos níveis de estresse total associados a menores índices de estresse nas subescalas: sofrimento parental (8.40 (100.00)), interação disfuncional pai e filho (5.61(100.00)) e criança difícil (3.15(99.84)).

\section{Tabela 1}

Associação entre indice de estresse parental e suas subescalas

\begin{tabular}{l|l|l|l}
\hline \multirow{2}{*}{ Subescalas } & \multicolumn{1}{c}{ Categorias } & \multicolumn{2}{c}{ Estresse Total } \\
\cline { 3 - 4 } & \multicolumn{2}{c}{ Baixa } & \multicolumn{1}{c}{ Alta } \\
\hline \multirow{2}{*}{$\begin{array}{l}\text { Sofrimento Parental } \\
\text { Interação Disfuncional Pai e } \\
\text { Filho }\end{array}$} & Baixo & $8.40(100.00)^{*}$ & $-11.56(0.00)$ \\
\cline { 2 - 4 } & Alto & $-9.63(0.00)$ & $13.25(100.00)^{*}$ \\
\hline \multirow{2}{*}{\begin{tabular}{l} 
Criança Difícil \\
\cline { 2 - 4 }
\end{tabular}} & Alta & $5.61(100.00)^{*}$ & $-7.72(0.00)$ \\
\hline
\end{tabular}

Nota. ${ }^{*}$ Probabilidades fortemente significativas, pois $\gamma \times 100 \geq 70 \% \gamma \times 100 \geq 70 \%$.

Já na Tabela 2, evidencia-se o cruzamento entre o estresse total do PSI e suas subescalas e o índice de coparentalidade geral. Observou-se baixos níveis de coparentalidade nos pais classificados com alto estresse total (1.32 (81.17)), principalmente nas subescalas sofrimento parental 
(1.58 (88.53)) e criança difícil com (3.69 (99.98)). Por outro lado, verificaram-se altos índices de coparentalidade nos pais com baixos níveis de estresse total com (1.07 (71.58)) e nas subescalas sofrimento parental $(2.33(98.00))$ e criança difícil com associação de $(2.34(98,07))$.

\section{Tabela 2}

Associaçóes entre indice de estresse parental e de coparentalidade

\begin{tabular}{l|lll}
\hline \multirow{2}{*}{ Variáveis } & \multirow{2}{*}{ Categorias } & \multicolumn{2}{c}{ Coparentalidade Geral } \\
\cline { 3 - 4 } & & \multicolumn{1}{c}{ Baixa } & \multicolumn{1}{c}{ Alta } \\
\hline \multirow{2}{*}{ Estresse total } & Baixo & $-0.78(0.00)$ & $1.07(71.58)^{*}$ \\
& Alto & $1.32(81.17)^{*}$ & $-1.81(0.00)$ \\
\hline \multirow{2}{*}{ Sofrimento Parental } & Baixo & $-1.38(0.00)$ & $2.33(98.00)^{*}$ \\
& Alto & $1.58(88.53)^{*}$ & $-2.67(0.00)$ \\
\multirow{2}{*}{ Interação disfuncional pai e filho } & Baixa & $1.25(78.84)^{*}$ & $-2.11(0.00)$ \\
& Alta & $-1.59(0.00)$ & $2.68(99.27)^{*}$ \\
\hline \multirow{2}{*}{ Criança difícil } & Baixo & $-1.38(0.00)$ & $2.34(98.07)^{*}$ \\
& Alto & $3.69(99.98) *$ & $-6.24(0.00)$ \\
\hline
\end{tabular}

Nota. ${ }^{*}$ Probabilidades fortemente significativas, pois $\gamma \times 100 \geq 70 \% \gamma \times 100 \geq 70 \%$.

Por fim, na Tabela 3, notam-se os achados resultantes a partir do cruzamento entre o Estresse total e suas subescalas e as subescalas do questionário de coparentalidade. Evidenciouse que em pais com baixa cooperação foram registrados elevados índices de estresse parental apenas na subescala sofrimento parental $(0.82$ (58.61)) e baixos níveis de estresse na escala sofrimento parental $(1,20(77,16))$. Enquanto a alta cooperação foi encontrada naqueles pais com altos níveis de estresse total $(2.50$ (98.77)) e nas subescalas interação disfuncional pai e filho $(7.56(100.00))$ e criança difícil com (3.39 (99.93)). 50\% $\leq \gamma \times 100<70 \%$ $50 \% \leq \gamma \times 100<70 \% \gamma \times 100 \geq 70 \% \gamma \times 100 \geq 70 \%$

Sobre a triangulação, verificou-se que ela foi baixa naqueles pais com baixo estresse total $(0.87(61.55))$ e nas subescalas sofrimento parental $(1.00(68.24))$ e criança difícil com (0.69 (51.07). Entretanto, elevados níveis de triangulação foram observados naqueles com alto estresse total (1.96 (94.99)), sofrimento parental (1.88 (93.94)) e criança difícil (3.02 (99.75)).

Por último, os dados também revelam associação entre baixo conflito e baixos índices de estresse total (3.12 (99.82)) e as demais subescalas: sofrimento parental (1.55 (87.93)), interação disfuncional pai e filho (2.74 (99.39)) e criança difícil (0.81 (58.25)). Do mesmo modo, verificou-se que a associação entre elevado conflito e altos níveis de estresse total foi alta nos pais com elevados níveis de estresse total (7.49 (100.00)), sofrimento parental (3.11 (99.81)), interação disfuncional pai e filho $(6.08$ (100.00)) e criança difícil (3.77 (99.98)). 


\section{Tabela 3}

Associaçôes entre o indice de estresse parental e as subescalas do questionário de coparentalidade

\begin{tabular}{|c|c|c|c|c|c|c|c|}
\hline & & \multicolumn{2}{|c|}{ Cooperaçáo } & \multicolumn{2}{|c|}{ Triangulação } & \multicolumn{2}{|c|}{ Conflito } \\
\hline & & Baixa & Alta & Baixa & Alta & Baixo & Alto \\
\hline \multirow{2}{*}{ Estresse total } & Baixo & $1.08(71.81)^{*}$ & $-1.82(0.00)$ & $0.87(61.55)^{* *}$ & $-1.42(0.00)$ & $3.12(99.82) *$ & $-5.45(0.00)$ \\
\hline & Alto & $-1.48(0.00)$ & $2.50(98.77)^{*}$ & $-1.20(0.00)$ & $1,96(94.99) *$ & $-4.29(0.00)$ & $7.49(100.00)^{*}$ \\
\hline \multirow{2}{*}{$\begin{array}{l}\text { Sofrimento } \\
\text { parental }\end{array}$} & Baixo & $-0.71(0.00)$ & $1.20(77.16) *$ & $1.00(68.24)^{* *}$ & $-1.64(0.00)$ & $1.55(87.93) *$ & $-2.71(0.00)$ \\
\hline & Alto & $0.82(58.61)^{* *}$ & $-1.38(0.00)$ & $-1.15(0.00)$ & $1.88(93.94)^{*}$ & $-1.78(0.00)$ & $3.11(99.81)^{*}$ \\
\hline \multirow{2}{*}{$\begin{array}{l}\text { Interaçấo disfun- } \\
\text { cional pai e filho }\end{array}$} & Baixa & $2.65(99.19) *$ & $-4.47(0.00)$ & \multirow{2}{*}{$p=0,248$} & & $2.74(99.39) *$ & $-4.79(0.00)$ \\
\hline & Alta & $-4.47(0.00)$ & $7.56(100.00)^{*}$ & & & $-3.48(0.00)$ & $6.08(100.00)^{*}$ \\
\hline \multirow{2}{*}{ Criança difícil } & Baixo & $0.75(54.77)^{* *}$ & $-1.27(0.00)$ & $0.69(51.07)^{* *}$ & $-1.13(0.00)$ & $0.81(58.25)^{* *}$ & $-1.42(0.00)$ \\
\hline & Alto & $-2.00(0.00)$ & $3.39(99.93) *$ & $-1.84(0.00)$ & $3.02(99.75) *$ & $-2.16(0.00)$ & $3.77(99.98)^{*}$ \\
\hline
\end{tabular}

Nota. **Probabilidades moderadamente significativas, pois $50 \% \leq \gamma \times 100<70 \% 50 \% \leq \gamma \times 100<70 \%$. *Probabilidades fortemente significativas, pois $\gamma \times 100 \geq 70 \% \gamma \times 100 \geq 70 \%$.

\section{Discussáo}

Sobre as características dos cuidadores investigados, a maioria era do sexo feminino, com idade aproximadamente de 33 anos, casados, com escolaridade até o Ensino Médio, ocupação do lar e com renda mensal de até dois salários-mínimos, sendo predominantemente beneficiários de programas do governo. Vale ressaltar que prioritariamente foram as máes que receberam a notícia do diagnóstico antes de 12 meses de idade de seu filho. Elas relataram as causas como perinatais devido a quadros de prematuridade e anóxia.

Em termos gerais, os achados revelam forte associação, seja positiva ou negativa, da coparentalidade com o estresse parental e as dimensóes do PSI, sofrimento parental e criança difícil. Esse dado demonstra que, de fato, o constructo coparentalidade consiste em um processo que se desenvolve no jogo estabelecido entre os membros que compóem o casal com a criança (Margolin et al., 2001). Nesse contexto relacional, as características dos adultos e das crianças são fundamentais e podem, por sua vez, se revelar nos itens que avaliam as dimensóes sofrimento parental e criança difícil mensurados pelo PSI.

Ao relacionar-se o estresse parental total, as dimensões do PSI com a classificação da coparentalidade, observou-se o papel fundamental exercido pela coparentalidade. De fato, os dados evidenciam que níveis altos de coparentalidade podem amortecer as experiências estressantes vividas pelos cuidadores de crianças com PC, aliviando o estresse nas três dimensóes avaliadas pelo PSI (sofrimento parental, Interação disfuncional pai e filho e criança difícil). Esse dado revela que a despeito das adversidades ocasionadas pela deficiência, os cuidadores que desenvolveram padróes adequados de coparentalidade conseguiram implementar estratégias mais bem-sucedidas de enfrentamento das adversidades cotidianas geradas pela deficiência do que aqueles cuidadores que não conseguiram desenvolver relaçóes coparentais apropriadas. Esse resultado é coerente com estudos que destacam a capacidade de crescimento e desenvolvimento das potencialidades positivas dos organismos e dos sistemas familiares (Seligman \& Csikszentmihalyi, 2000) 
A análise detalhada das dimensões do psi e do questionário de coparentalidade revelaram que cuidadores com alto nível de estresse apresentaram alto nível de sofrimento parental e, por sua vez, quando aplicada a análise de correspondência, observaram-se associaçóes com baixo nível de cooperaçáo. Esse dado é congruente com a literatura que aponta a mãe como a principal e, em alguns casos, a única cuidadora da prole, e que, diante da ocorrência de um filho com deficiência, a sobrecarga de cuidados é dobrada (Silva et al., 2019). Tal sobrecarga pode ser amenizada quando há divisão de cuidados parentais, suporte social (Lima et al., 2016), assim como características sociodemográficas de menor risco, como renda familiar mais elevada (Veiga-Branco et al., 2018).

Pais de crianças com PC com baixos níveis de estresse foi o objeto de interesse de um estudo qualitativo (Cunha et al., 2017). Nele, os autores buscaram identificar fatores de risco e de proteção nos discursos de sete pais submetidos a um grupo focal, baseando-se na perspectiva teórica da Bioecologia do desenvolvimento de Bronfenbrenner. Dentre os resultados encontrados, destacam-se as redes de apoio conjugal, familiar e de amigos, acesso à informação e recurso econômico.

O resultado do cruzamento das dimensóes do psi com as dimensóes do questionário de coparentalidade confirma o papel central da dimensão cooperação. Cuidadores que recebiam mais ajuda do parceiro e suporte apresentaram níveis menores de estresse. A literatura sugere que o bom funcionamento da rede conjugal pode funcionar como importante fonte de apoio a cuidadores de crianças com PC (Souza et al., 2018).

Segundo as evidências empíricas, são muitos os aspectos que podem contribuir com a geração do estresse parental. No entanto, é consenso que as características da criança com PC constituem fatores causadores de estresse parental (Brito \& Faro, 2016). Os altos índices de estresse no item criança difícil do PSI, mesmo naqueles pais com alta cooperação, pode estar relacionado ao fato de que a maioria das crianças do presente estudo estavam classificadas nos níveis mais graves de funcionalidade de acordo com o GMFCS, com idade média de 6 anos e peso aproximado de 17,8 quilos, o que contribui para a sobrecarga do cuidador (Lima et al., 2016).

A característica da criança tem sido apontada como causa direta de adoecimento físico de pais, principalmente devido à dificuldade de reciprocidade de afeto nos casos mais graves da PC (Ribeiro et al., 2016; Rodriguez-JenKins \& Marcenko, 2014). Essa dificuldade de estabelecer relaçóes positivas e favorecedoras do desenvolvimento humano pode ser representada pelos conflitos nas tomadas de decisão sobre os cuidados com o filho, o que sem dúvida pode colaborar com o sofrimento no exercício parental.

A relação entre pais e filhos vem sendo explorada por diversas áreas do desenvolvimento humano. Essas práticas parentais, como é denominada, pode apresentar-se de forma positiva ou negativa (Schmidt et al., 2016). Parece lógico pensar que a existência de altos níveis de estresse na subescala interação disfuncional pai e filho podem estar associadas a falta de par coparental para o compartilhamento das demandas de cuidados dispensados ao filho com PC, porém a presente pesquisa mostrou que a maioria dos entrevistados são casados, evidenciando que a presença de um cônjuge não garante o seu papel efetivo nos cuidados da criança com PC. Por outro lado, vale ressaltar que o baixo conflito revelado pelo estudo pode estar relacionado ao fato de que a maioria dos cuidadores exerciam de forma exclusiva a função de cuidar 
da criança e do lar, não exercendo outra ocupação, o que contribui, de certa forma, para um isolamento social do convívio de outros adultos e afastando-os de atividades de lazer (Souza et al., 2018).

\section{Conclusão}

Esta pesquisa mostrou a forte associação entre estresse parental e coparentalidade, evidenciando o papel amortecedor exercido pela coparentalidade, uma vez que cuidadores de crianças com PC que apresentaram relaçóes coparentais altas foram classificados com níveis menores de estresse. Adicionalmente, a dimensão cooperação destacou-se na investigação, uma vez que esta esteve associada à dimensão sofrimento parental, o que indica que cuidadores que dispóem de relaçóes menos cooperativas apresentam níveis maiores de estresse nessa última dimensão. A característica da criança, expressa na dimensão do psi criança difícil, influenciou no estresse parental total e na coparentalidade geral, o que confirma a natureza sistêmica do funcionamento familiar.

Entende-se que a presente pesquisa apresenta inúmeros achados, dentre estes destaca-se o oferecimento de conhecimento que aponta para a necessidade de fortalecimento do sistema familiar de crianças com deficiência como um todo, de modo particular o sistema conjugal, visto que este é o principal responsável pela qualidade de vida dessas crianças. Nesse sentido, os cuidadores precisam ser instrumentalizados com vistas a reconhecerem náo somente seu papel, mas também suas capacidades, assim como desenvolverem habilidades de cooperação para promover o desenvolvimento de seus filhos com deficiência.

A despeito das contribuiçóes deste estudo, reconhece-se que esta pesquisa apresenta limitações. Acredita-se que os achados poderiam ficar mais evidentes caso tivesse sido possível realizar a coleta com um número maior de participantes, com características diversas, o que possibilitaria formar diferentes grupos para análise. Desse modo, sugere-se que estudos futuros ampliem o número de participantes, incluindo cuidadores de crianças com diferentes tipos de deficiência e considerem os paramentos de coparentalidade em grupo controle.

\section{REFERÊNCIAS}

Afonso, T., Ramos, M. F. H., França, I. L., Pontes, F. A. R., \& Silva, S. S. D. C. (2016). Cuidado parental à criança com paralisia cerebral: uma revisão sistemática da literatura. Revista Brasileira de Educação Especial, 22(3), 455-470. https://doi.org/10.1590/S1413-65382216000300011

Brito, A. de, \& Faro, A. (2016). Estresse parental: Revisão sistemática de estudos empíricos. Psicologia em Pesquisa, 10(1), 64-75. https://dx.doi.org/10.24879/201600100010048

Cunha, K. D. C., Ramos, M. F. H., Silva, S. S. D. C., \& Pontes, F. A. R. (2017). Estresse parental e paralisia cerebral. Psicologia, Saúde \& Doenças, 18(2), 433-450. https://doi.org/10.15309/17psd180212.

Dantas, C. R., Féres-Carneiro, T., Machado, R. N., \& Magalhães, A. S. (2018). A díade madrasta-enteado: narrativas no contexto do recasamento. Psico-USF, 23(1), 37-46. http://doi.org/10.1590/141382712018230104 . 
Feinberg, M. (2003). The internal structure and ecological context of coparenting: A framework for research and intervention. Parenting: Science and Practice, 3(2), 95- 131. https:/doi. org/10.1207\%2FS15327922PAR0302_01

Frizzo, G. B., Schmidt, B., Vargas, V. D., \& Piccinini, C. A. (2019). Coparentalidade no Contexto de Depressão Pós-Parto: Um Estudo Qualitativo. Psico-USF, 24(1), 85-96. http://doi. org/10.1590/1413-82712019240107.

Lamela, D., \& Figueiredo, B. (2016). Coparentalidade após a dissolução conjugal e saúde mental das crianças: uma revisão sistemática. Journal de Pediatria, 92(4), 331- 342. http://doi.org/10.1016/j. jped.2015.09.011

Lamela, D., Nunes-Costa, R., \& Figueiredo, B. (2010). Modelos teóricos das relaçóes coparentais: revisão crítica. Psicologia em Estudo, 15(1), 205-216.

Lima, M. B. S., Cardoso, V. D. S., \& Silva, S. S. D. C. (2016). Parental stress and social support of caregivers of children with cerebral palsy. Paidéia (Ribeirão Preto), 26(64), 207-214. http://doi. org/10.1590/1982-43272664201608

Margolin, G., Gordis, E. B., \& John, R. S. (2001). Coparenting: A link between marital conflict and parenting in two-parent families. Journal of Family Psychology, 15, 3-21. https://doi. org/10.1037/0893-3200.15.1.3

Mosmann, C., Costa, C. B. D., Silva, A. G. M. D., \& Luz, S. K. (2018). Children with clinical psychological symptoms: the discriminant role of conjugality, coparenting and parenting. Trends in Psychology, 26(1), 429-442. http://doi.org/10.9788/tp2018.1-17pt

Palisano, R., Rosenbaum, P., Bartlett, D., \& Livingston, M. (2007). Gross Motor Function Classification System-Expanded and Revised. CanChild Centre for Childhood Disability Research, McMaster University. Institute for Applied Health Sciences McMaster University, Hamilton, Ontario, b15.

Papageorgiou, E., Nieuwenhuys, A., Vandekerckhove, I., Van Campenhout, A., Ortibus, E., \& Desloovere, K. (2019). Systematic review on gait classifications in children with cerebral palsy: an update. Gait \& Posture, 69, 209-223. https://doi.org/10.1016/j.gaitpost.2019.01.038

Pereira, L. M., Viera, C. S., Toso, B. R. G. de O., Carvalho, A. R. da S., \& Bugs, B. M. (2016). Validação da escala Índice de Estresse Parental para o português do Brasil. Acta Paulista de Enfermagem, 29(6), 671-677. http://doi.org/10.1590/1982-0194201600094

Ramos, E. M. L. S., Almeida, S. S, \& Araújo, A. R. (2008). Segurança Pública: Uma abordagem Estatística e Computacional. Edufpa.

Resolução No 466, de 12 de dezembro de 2012. Recuperado em 25 outubro de 2020 de https://bvsms. saude.gov.br/bvs/saudelegis/cns/2013/res0466_12_12_2012.html

Ribeiro, M. F. M., Santos, I., Campos, A., Gomes, M., Formiga, C. K. M. R., \& Prudente, C. (2016). Mães de crianças, adolescentes e adultos com Síndrome de Down: Estresse e estratégias de enfrentamento. Investigação Qualitativa em Saúde, 2, 1396-1405.

Rodriguez-Jenkins, J., \& Marcenko, M. O. (2014). Parenting stress among child welfare involved families: Differences by child placement. Children and Youth Services Review, 46, 19-27. http://doi. org/10.1016/j.childyouth.2014.07.024

Romero, M. P. (2015). Coparentalidade: desafios para o casamento contemporâneo (Dissertação de Mestrado). Pontifícia Universidade Católica do Rio de Janeiro, Rio de Janeiro, Brasil. 
Schmidt, B., Staudt, A. C. P., \& Wagner, A. (2016). Intervençóes para promoção de práticas parentais positivas: uma revisão integrativa. Contextos Clínicos, 9(1), 1-18. https://dx.doi.org/10.4013/ ctc.2016.91.01

Seligman, M. E. P., \& Csikszentmihalyi, M. (2000). Positive psychology: an introduction. American Psychologist, 55(1), 5-14.

Silva, Í. D. C. P., Cunha, K.C., Ramos, E. M. L. S., Pontes, F. A. R., \& Silva, S. S. C. (2019). Estresse parental em famílias pobres. Psicologia em Estudo, 24. 1-17. https://doi.org/10.4025/psicolestud. v24i0.40285

Skreden, M., Skari, H., Malt, U. F., Pripp, A. H., Björk, M. D., Faugli, A., \& Emblem, R. (2012). Parenting stress and emotional wellbeing in mothers and fathers of preschool children. Scand Journal of Public Health, 40, 596-604. http://doi.org/10.1177/1403494812460347

Souza, J. D., \& Crepaldi, A. M. (2019). Emotional and Behavioral Problems of Children: Association between Family Functioning, Coparenting and Marital Relationship. Acta Colombiana de Psicología, 22(1), 82-94. http://doi.org/10.14718/ACP.2019.22.1.5

Souza, J. M., Machado, F. R. C., Antunes, P. P., Santos, A. C., Levandoswki, D. C., \& Oliveira Junior, A. A. (2018). Qualidade de vida e sobrecarga de cuidadores de crianças com paralisia cerebral. Revista Brasileira em Promoção da Saúde, 31,1-10. https://doi.org/10.5020/18061230.2018.7748

Van Egeren, L. A., \& Hawkins, D. P. (2004). Coming to terms with coparenting: Implications of definition and measurement. Journal of Adult Development, 11(3), 165-178.

Veiga-Branco, M. A. R., Ribeiro, M. I. B., Antão, C. D. C. M., \& Anastácio, Z. C. (2018). Relação entre stress parental e as características socioeconómicas de pais de crianças com necessidades especiais. International Journal of Developmental and Educational Psychology. Revista INFAD de Psicología. 3(1), 219-228.

Recebido em: 27/01/2020

Reformulado em: 18/07/2020

Aprovado em: 17/10/2020 